\title{
Antiplasmodial potential and quantification of aloin and aloe-emodin in Aloe vera collected from different climatic regions of India
}

Sandeep Kumar, Manila Yadav, Amita Yadav, Pooja Rohilla and Jaya Parkash Yadav (1)

\begin{abstract}
Background: In this study, Aloe vera samples were collected from different climatic regions of India. Quantitative HPTLC (high performance thin layer chromatography) analysis of important anthraquinones aloin and aloe-emodin and antiplasmodial activity of crude aqueous extracts was done to estimate the effects of these constituents on antiplasmodial potential of the plant.
\end{abstract}

Methods: HPTLC system equipped with a sample applicator Linomat $V$ with CAMAG sample syringe, twin rough plate development chamber $(20 \times 10 \mathrm{~cm})$, TLC Scanner 3 and integration software WINCATS 1.4.8 was used for analysis of aloin and aloe-emodin amount. The antiplasmodial activity of plant extracts was assessed against a chloroquine (CQ) sensitive strain of P. falciparum (MRC-2). Minimum Inhibitory Concentration (MIC) of aqueous extracts of selected samples was determined according to the World Health Organization (WHO) recommended method that was based on assessing the inhibition of schizont maturation in a 96-well microtitre plate. EC (effective concentration) values of different samples were observed to predict antiplasmodial potential of the plant in terms of their climatic zones.

Results: A maximum quantity of aloin and aloe-emodin i.e. 0.45 and $0.27 \mathrm{mg} / \mathrm{g}$ respectively was observed from the 12 samples of Aloe vera. The inhibited parasite growth with $\mathrm{EC}_{50}$ values ranging from 0.289 to $1056 \mu \mathrm{g} / \mathrm{ml}$. The antiplasmodial $\mathrm{EC}_{50}$ value of positive control Chloroquine was observed $0.034 \mu \mathrm{g} / \mathrm{ml}$ and $\mathrm{EC}_{50}$ values showed by aloin and aloe-emodin was $67 \mathrm{\mu g} / \mathrm{ml}$ and $22 \mu \mathrm{g} / \mathrm{ml}$ respectively. A positive correlation was reported between aloin and aloe-emodin. Antiplasmodial activity was increased with increase in the concentration of aloin and aloe-emodin. The quantity of aloin and aloe-emodin was decreased with rise in temperature hence it was negatively correlated with temperature.

Conclusions: The extracts of Aloe vera collected from colder climatic regions showed good antiplasmodial activity and also showed the presence of higher amount of aloin and aloe-emodin in comparison to collected from warmer climatic sites. Study showed significant correlation between quantities of both the anthraquinones used as marker compounds and $\mathrm{EC}_{50}$ values of the different Aloe vera extracts. Although, both the anthraquinones showed less antiplasmodial potential in comparison to crude extracts of different Aloe vera samples. Diverse climatic factors affect the quantity of tested compounds and antiplasmodial potential of the plant in different Aloe vera samples.

Keywords: Quantitative analysis, Aloe vera, Anthraquinone, Climatic zone, Antiplasmodial

\footnotetext{
* Correspondence: yadav1964@rediffmail.com

Department of Genetics, Maharshi Dayanand University, Rohtak, Haryana

-124001, India
} 


\section{Background}

Throughout the history of mankind, malaria has been one of the major causes of human illness and death. More than 800,000 deaths occur every year; the vast majority being children under the age of five. Thus this highly infectious disease has a global impact. Malaria is a parasitic disease widespread in tropical and subtropical regions of the world [1, 2]. It is endemic particularly in regions of Africa, Asia and South America. India's extensive geography and diverse climate supports ideal environments for sustaining malarial parasites and their vectors [3]. Malaria can be diagnosed easily on morphological basis at different stages of parasite in human blood; with the exception of P. falciparum. [4]. P. falciparum is the most severe strain of the malaria due to highest human deaths and resistant to standard antimalarial drugs. [5]. The WHO has recommended artemisininbased combination therapy (ACT) as the first line treatment for multidrug resistant malaria caused by $P$. falciparum in different parts of the word [6]. Recent studies have reported that $P$. falciparum has developed resistance to many of available antimalarial drugs [7-9].

Malaria has become a leading cause of morbidity and mortality mainly due to its prevalence in poor resource countries; where the therapy is unaffordable due to nonavailability of oral administered drugs [10]. As antimalarial drug resistance is undermining the effective treatment of the disease; there is a critical need for effective, safe, and affordable antimalarial agents. Herbal medicine occupies a pivotal role in treating infectious diseases since onset of mankind. It is estimated that about $40 \%$ of all medicines is either natural products or their semi-synthetic derivatives [11].

Natural products may offer relatively cheap alternative treatment opportunities for malaria patients due to vast metabolic diversity [12-14]. Currently used antimalarial drugs such as quinine and artemisinin were both isolated from plants Cinchona officinalis and Artemisia annua respectively. Consequently, it has been established that plants have potential as sources for antimalarial drugs. The diverse climates of India flourish huge diversity of medicinal plants and use of plants for treating ailments tracks back to ancient Indian [15].

Quality evaluation and pharmacological standardization of herbal preparation is a fundamental requirement of industry for commercial production. According to WHO guidelines, an herbal product needs to be standardized with respect to safety before releasing it into the market [16]. HPTLC (high performance thin layer chromatography) is an inexpensive method for separation, qualitative identification, or semi-quantitative analysis of samples and it can be used to solve many qualitative and quantitative analytical problems in a wide range of fields; including medicine, pharmaceuticals, chemistry, biochemistry, food analysis, toxicology and environmental analysis [17].

Aloe vera (syn.: Aloe barbadensis Miller) is the most commercialized Aloe species belonging to the Xanthorrhoeaceae family $[18,19]$. There are many natural medicinal herbs, but Aloe vera possesses a vast array of healing benefits. Owing to its multipurpose utility, Aloe has been introduced into cultivation as a household plant. It has been in use since ages as folk medicine. Aloe vera is a rich source of over 200 naturally occurring nutrients which contain water soluble and fat soluble vitamins, minerals, enzymes, polysaccharides, phenolic compounds and organic acids [20]. Its secondary metabolites have multiple properties such as anti-inflammatory, antibacterial, antioxidant, immune boosting, anticancer, antiageing, sunburn relief and antidiabetic potentials [21-23]. Several traditional uses also have been reported such as burn injury, eczema, cosmetics, inflammation, and fever [24]. Aloe juice mixed with water and honey is used as an effective antimalarial cure in Yemen [25].

Recently Aloe vera was reported to be used against malaria parasite with the highest frequency in a documentation report on medicinal plants used by the local communities of western Uganda [26]. Van Zyl and Viljoen [27] screened the main constituents of 34 Aloe species for antiplasmodial activity using the titrated hypoxanthine incorporation assay. They have observed that methanol extracts possessed antiplasmodial activity against Plasmodium falciparum strain at concentration ranged from 32 to $77 \mu \mathrm{g} \mathrm{ml}^{-1}$ where $50 \%$ of the parasite growth was inhibited ( $\mathrm{IC}_{50}$ value) [27]. The Aloe species of $A$. secundiflora and $A$. lateritia were also used for treating malaria and related symptoms [28].

Geographical conditions are the main factors that ultimately affect the phytoconstituents and medicinal properties of a plant. India has six major climatic zones: Highland, semi-arid, arid, tropical wet, tropical wet and dry, and humid subtropical climate. Aloe vera grows all over the India, wildly in Maharashtra and Tamil Nadu states where as Andhra Pradesh, Gujarat and Rajasthan states are known for its cultivation. [29]. So, keeping in view of the importance of Aloe vera plant the present work is an attempt to evaluate the antiplasmodial activity and phytochemical standardization of Aloe vera aqueous extracts with HPTLC; collected from different climatic regions of India to elaborate the effect of climatic conditions on phytochemical diversity and activity of samples.

\section{Methods}

\section{Plant collection}

Samples were collected from 12 different sites of north to south India covering 6 agro-climatic zones of India. Each zone had 2 sites (Fig. 1). Geographical locations of 


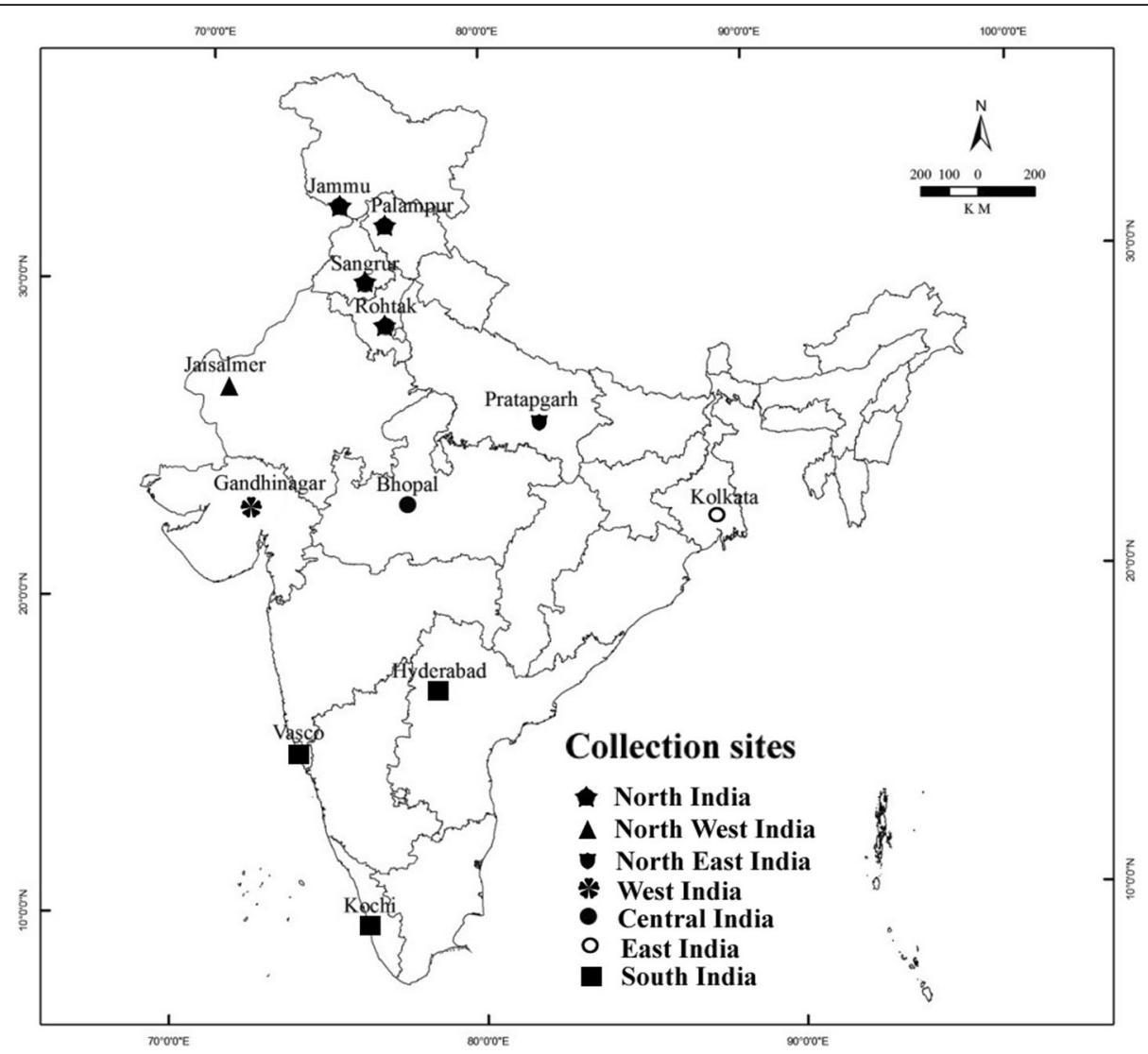

Fig. 1 Map showing Aloe vera sample collection sites from different places of India

collection sites along with their average temperature and rainfall are depicted in Table 1. Samples were collected in the months of January and February 2013. Healthy leaves of Aloe vera were collected from individual wild plants at each location. The plant material was identified and authenticated by comparing the herbarium specimen (MDU-6803) available in Department of Genetics, M. D. University, Rohtak (India). Tissues were placed in sterile plastic bags. All samples were brought to the laboratory in an ice box and processed further.

\section{Extract preparation}

The samples were first washed with tap water and then surface sterilised in $10 \%$ sodium hypochlorite to prevent the contamination of any microbes [30]. They were thoroughly rinsed with sterile distilled water. The plant samples were shade dried followed by oven drying $\left(50{ }^{\circ} \mathrm{C}\right)$ and milled in an electrical blender. Aqueous extracts of different accessions were prepared by cold percolation method. The extracts were pooled, and the solvent was evaporated using a rotary evaporator under reduced pressure at $40{ }^{\circ} \mathrm{C}$. The crude extracts thus obtained were kept at $4{ }^{\circ} \mathrm{C}$ for antiplasmodial assay.

\section{HPTLC analysis}

A CAMAG (Muttenz, Switzerland) HPTLC system equipped with a sample applicator Linomat $\mathrm{V}$ with CAMAG sample syringe, $100 \mu$ l, twin rough plate development chamber $(20 \times 10 \mathrm{~cm})$, TLC Scanner 3 and integration software WINCATS 1.4.8 was used. CAMAG TLC visualiser (Professional photo documentation system) was used for capturing the coloured images of the developed TLC plate and other documentation purposes. An aluminium supported HPTLC plate $(20 \times 10 \mathrm{~cm})$ precoated with silica gel 60F 254 (E. Merck) was used as an adsorbent. CAMAG TLC plate heater was used to preactivation of the HPTLC plates and for drying the developed plates. The experimental conditions maintained were temperature $25 \pm 2{ }^{\circ} \mathrm{C}$, relative humidity $40 \%$.

TLC method was used for estimation of aloin and aloe-emodin content in different samples of Aloe vera using standard berberine as biomarker. HPTLC precoated plates Silica Gel Merck 60F254 was used as a stationary phase.

Aloe vera aqueous extract of different samples was made to attain the final concentration of $1000 \mu \mathrm{g} / \mathrm{ml}$. A $1000 \mu \mathrm{g} / \mathrm{ml}$ solution of aloin and aloe-emodin reference standard was prepared in water as a stock 
Table 1 Geographical parameters, crude extract yield, yield of aloin and aloe-emodin and antiplasmodial EC 50 values of Aloe vera aqueous extracts collected from different sites of India

\begin{tabular}{|c|c|c|c|c|c|c|c|c|c|c|c|}
\hline \multirow[t]{2}{*}{$\begin{array}{l}\text { Sr. } \\
\text { No. }\end{array}$} & \multirow[t]{2}{*}{$\begin{array}{l}\text { Agro-climatic } \\
\text { zones }\end{array}$} & \multirow[t]{2}{*}{$\begin{array}{l}\text { Collection } \\
\text { sites }\end{array}$} & \multirow[t]{2}{*}{$\begin{array}{l}\text { Place of } \\
\text { collection }\end{array}$} & \multirow[t]{2}{*}{$\begin{array}{l}\text { Average } \\
\text { Temp. }\left({ }^{\circ} \mathrm{C}\right) .\end{array}$} & \multirow{2}{*}{$\begin{array}{l}\text { Average } \\
\text { Rainfall } \\
(\mathrm{mm}) .\end{array}$} & \multirow{2}{*}{$\begin{array}{l}\text { Crude Extract } \\
\text { Yield } \\
\text { (g/100 g) }\end{array}$} & \multicolumn{2}{|c|}{$\begin{array}{l}\text { Aloin Yield out } \\
\text { of crude extract }\end{array}$} & \multicolumn{2}{|c|}{$\begin{array}{l}\text { Aloe-emodin Yield } \\
\text { out of crude extract }\end{array}$} & \multirow{2}{*}{$\begin{array}{l}\mathrm{EC}_{50}(\mu \mathrm{g} / \mathrm{ml}) \text { for } \\
\text { antiplasmodial } \\
\text { activity }\end{array}$} \\
\hline & & & & & & & $(\mathrm{mg} / \mathrm{g})$ & $\%$ yield & $(\mathrm{mg} / \mathrm{g})$ & $\%$ yield & \\
\hline 1 & Highland & $\begin{array}{l}\text { Jammu and } \\
\text { Kashmir [J\&K] }\end{array}$ & Jammu & 13.5 & 1011 & 3.7 & $0.45 \pm 0.061$ & 1.21 & $0.23 \pm 0.054$ & 0.62 & $0.441 \pm 0.093$ \\
\hline 2 & & $\begin{array}{l}\text { Himachal } \\
\text { Pradesh [H.P.] }\end{array}$ & Palampur & 13.5 & 1251 & 3.5 & $0.45 \pm 0.043$ & 1.28 & $0.21 \pm 0.008$ & 0.60 & $0.289 \pm 0.032$ \\
\hline 3 & Semi-arid & Punjab & Sangrur & 25 & 649 & 3.9 & $0.32 \pm 0.050$ & 0.82 & $0.29 \pm 0.066$ & 0.74 & $0.472 \pm 0.012$ \\
\hline 4 & & Haryana & Rohtak & 27 & 617 & 4.1 & $0.39 \pm 0.022$ & 0.95 & $0.11 \pm 0.037$ & 0.27 & $0.407 \pm 0.085$ \\
\hline 5 & Arid & Rajasthan & Jaisalmer & 28.5 & 209.5 & 3.5 & $0.37 \pm 0.034$ & 1.06 & $0.27 \pm 0.029$ & 0.77 & $0.980 \pm 0.007$ \\
\hline 6 & & Gujarat & Gandhinagar & 27.5 & 1107 & 3.8 & $0.21 \pm 0.067$ & 0.55 & $0.13 \pm 0.043$ & 0.34 & $0.621 \pm 0.036$ \\
\hline 7 & $\begin{array}{l}\text { Humid } \\
\text { Subtropical }\end{array}$ & $\begin{array}{l}\text { Uttar Pradesh } \\
\text { [U.P.] }\end{array}$ & Pratapgarh & 25.5 & 904 & 3.9 & $0.33 \pm 0.041$ & 0.85 & $\begin{array}{l}\text { Peak not } \\
\text { detected }\end{array}$ & - & $0.299 \pm 0.059$ \\
\hline 8 & & $\begin{array}{l}\text { Madhya } \\
\text { Pradesh [MP] }\end{array}$ & Bhopal & 25.5 & 1146 & 3.0 & $0.22 \pm 0.074$ & 0.73 & $0.19 \pm 0.060$ & 0.63 & $0.689 \pm 0.027$ \\
\hline 9 & $\begin{array}{l}\text { Tropical } \\
\text { wet \& dry }\end{array}$ & $\begin{array}{l}\text { West Bengal } \\
\text { [W.B.] }\end{array}$ & Kolkata & 27 & 1582 & 3.4 & $0.17 \pm 0.037$ & 0.50 & $0.27 \pm 0.036$ & 0.79 & $0.417 \pm 0.041$ \\
\hline 10 & & Telangana & Hyderabad & 26.5 & 812.5 & 3.7 & $\begin{array}{l}\text { Peak not } \\
\text { detected }\end{array}$ & - & $\begin{array}{l}\text { Peak not } \\
\text { detected }\end{array}$ & - & $1056 \pm 0.033$ \\
\hline 11 & Tropical wet & Kerala & Kochi & 28 & 3005 & 3.6 & $\begin{array}{l}\text { Peak not } \\
\text { detected }\end{array}$ & - & $0.09 \pm 0.042$ & 0.25 & $0.558 \pm 0.047$ \\
\hline 12 & & Goa & Vasco & 27.5 & 3055 & 3.3 & $0.15 \pm 0.033$ & 0.45 & $0.20 \pm 0.040$ & 0.60 & $0.663 \pm 0.029$ \\
\hline
\end{tabular}

Positive control Chloroquine (CQ) value $=0.034 \pm 0.027 \mu \mathrm{g} / \mathrm{ml}$; aloin $=67 \pm 0.046 \mu \mathrm{g} / \mathrm{ml}$; aloe-emodin $=22 \pm 0.063 \mu \mathrm{g} / \mathrm{ml}$

solution. These solutions were used for further HPTLC analysis as per the developed protocol. Ethyl acetate, methanol and water in the ratio of 10:2:1 ( $/$ $\mathrm{v} / \mathrm{v})$ were used as a mobile phase.

The TLC plate $(10 \times 10 \mathrm{~cm})$ was pre-activated on TLC plate heater at $60{ }^{\circ} \mathrm{C}$ for $30 \mathrm{~min}$. For co-chromatography with aloin and emodin, $10 \mu \mathrm{l}$ of sample solution of aqueous extract along with the standard was applied on a TLC plate and the plate was developed in Ethyl acetate, methanol and water in the ratio of 10:2:1 $(\mathrm{v} / \mathrm{v} / \mathrm{v})$ solvent system to a distance of $8 \mathrm{~cm}$. The plates were dried at $120{ }^{\circ} \mathrm{C}$ temperature for $5 \mathrm{~min}$ using TLC plate heater. The plate was then kept inside TLC visualiser for resolving the coloured bands and for plate photo documentation. The Retardation factor $\left(R_{f}\right)$ values and colour of the resolved bands were noted.

\section{HPTLC densitometry analysis}

\section{Preparation of sample \& standard solution}

Sample solution (aqueous extract; $1000 \mu \mathrm{g} / \mathrm{ml}$ ) and standard solution $(1000 \mu \mathrm{g} / \mathrm{ml})$ described under the previous section was used for quantification of aloin and emodin.

\section{Preparation of calibration curve of \& quantification of aloin} and aloe-emodin

The different volume of standard stock solution 2, 4, 6, 8, 10 and $12 \mu \mathrm{l}$ were spotted on HPTLC plate $(20 \times 10 \mathrm{~cm})$ in order to deliver concentration of $4,6,8,10$ and $12 \mu \mathrm{g} /$ spot of aloin and aloe-emodin respectively using vial I and vial II respectively followed by spotting of $4 \mu \mathrm{l}$ of sample stock solution of 12 samples. Samples were applied as bands $4 \mathrm{~mm}$ wide, $12 \mathrm{~mm}$ apart, by CAMAG Linomat V applicator using $100 \mu \mathrm{l}$ sample syringe with a constant application rate of $150 \mathrm{nLs}^{-1}$. After sample application plates were developed in a developing chamber pre-saturated with the mobile phase $(20 \mathrm{ml})$ Ethyl acetate, methanol and water in the ratio of 10:2:1 $(\mathrm{v} / \mathrm{v} / \mathrm{v})$ for $20 \mathrm{~min}$. The plate was developed in CAMAG horizontal twin tough glass developing chamber $(20 \times 10 \mathrm{~cm})$ at the room temperature up to $8 \mathrm{~cm}$ ( $80 \%$ of the total plate size). Ascending mode was used for the development of thin layer chromatography.

After development, plates were dried on CAMAG TLC plate heater at $120{ }^{\circ} \mathrm{C}$ temperature for $5 \mathrm{~min}$. The plate was then observed under UV and fluorescence reflectance mode in CAMAG TLC visualiser photo documentation system at wavelength of 254 and $366 \mathrm{~nm}$ respectively. The coloured images of the developed plates were documented using WINCATS 1.4.8 software at both wavelengths 254 and $366 \mathrm{~nm}$. The developed plate was then scanned at $366 \mathrm{~nm}$ using CAMAG TLC densitometric scanner 3 integrated with WINCATS 1.4.8 software.

The calibration curve was prepared using standard concentration range of 4-12 $\mu \mathrm{g} / \mathrm{spot}$. Each concentration 
peak area was plotted against the concentration of aloin and aloe-emodin respectively spotted in densitometric analysis within the integrated software. Quantification of aloin and aloe-emodin was done as the peak areas of sample spots were recorded and the amount of aloin and aloe-emodin were calculated using standard curve.

\section{Antiplasmodial activity Parasite culture}

The antiplasmodial activity of plant extracts was assessed against a chloroquine (CQ)-sensitive strain of $P$. falciparum (MRC-2) obtained from the National Institute of Malaria Research, New Delhi, and maintained in continuous culture according to the methodology described by Trager and Jensen [31]. Parasites were cultivated in group $\mathrm{O}^{+}$human erythrocytes and suspended at a $4 \%$ hematocrit in RPMI-1640 medium supplemented with HEPES, $\mathrm{NaHCO}_{3}, 10 \% \mathrm{O}^{+}$human serum and neomycin at $37{ }^{\circ} \mathrm{C}$ in a controlled gas atmosphere of $2 \% \mathrm{O}_{2}, 5 \% \mathrm{CO}_{2}$ and $93 \% \mathrm{~N}_{2}$ in a $\mathrm{CO}_{2}$ incubator (Galaxy 170R, New Brunswick, USA).

\section{Minimum inhibitory concentration (MIC)}

The antiplasmodial activity of aqueous extracts of selected samples were performed in triplicate in a 96-well microtitre plate, according to the method of WHO that was based on assessing the inhibition of schizont maturation [32]. The culture was synchronised using 5\% (w/v) of sorbitol for $5 \mathrm{~min}$ at room temperature to ensure killing of all other stages except rings. It was centrifuged for $5 \mathrm{~min}$ at $1500 \mathrm{rpm}$. The supernatant was discarded, and the pellet was washed two times with incomplete media. Parasitaemia was adjusted to about $1 \%$ for the assay by diluting with freshly washed RBCs. The extracts were dissolved in DMSO to obtain the concentrations of $125,62.5,31.25,15.6,7.8,3.9$ and $1.9 \mu \mathrm{g} / \mathrm{mL}$. For the positive control wells, parasitized red blood cells were devoid of extracts, whereas only non-parasitized red blood cells were prepared for the negative control wells. Fifty microlitres of blood mixture media was added to each well in the plate and incubated in controlled gas atmosphere of $2 \% \mathrm{O}_{2}, 5 \% \mathrm{CO}_{2}$ and $93 \% \mathrm{~N}_{2}$ at $37{ }^{\circ} \mathrm{C}$ for 24-36 h in a $\mathrm{CO}_{2}$ incubator.

After incubation, contents of the wells were harvested and stained for $30 \mathrm{~min}$ in a $2 \%$ Giemsa solution $\left(\mathrm{pH}\right.$ 7.2). The $\mathrm{EC}_{50}$ value for the standard drug CQ (Chloroquine) was also recorded. The developed schizonts were counted against the total asexual parasite count of 200 .

\section{Statistical analysis}

Effective concentration of the extracts was determined by using software HN-NonLin V1.1. $\mathrm{EC}_{50}$ values, indicating the concentration of the extract required to obtain $50 \%$ inhibition of parasite growth, were calculated by linear regression analysis with three replicates. Pearson coefficient method was used to exhibit correlation between quantitative phytochemicals analyses and antiplasmodial activity of each extracts. Correlation between aloin, aloe-emodin quantity, $\mathrm{EC}_{50}$ values, temperature and rainfall of each collection sites was calculated using SPSS software version 16.

\section{Results}

The yields of crude aqueous extracts alongwith aloin and aloin-emodin have been depicted in Table 1.

\section{HPTLC analysis}

Developed TLC method resolved the aloin at $R_{f}$ value of nearly about 0.80 and aloe-emodin at 0.83 confirming presence of aloin and aloe-emodin in plant extracts visualised by bluish/blackish band parallel to aloin and aloe-emodin spot along with other resolved components in developed TLC plate.

\section{HPTLC densitometry analysis}

The spot at $R_{\mathrm{f}} 0.80$ was identified as aloin and at 0.83 was identified as aloe-emodin with the help of chromatogram of the standard compound and HPTLC plate image at $254 \mathrm{~nm}$ and $366 \mathrm{~nm}$. The well defined spots were obtained upon complete saturation of the solvent chamber for $30 \mathrm{~min}$. The peak corresponding to aloin and emodin from the sample solution had same retention factor as that from aloin and emodin standard ( $\mathrm{rf}$ 0.80 and 0.83 ). From the standard curve of aloin and aloe-emodin quantification of standards were done which revealed the amount of aloin and aloe-emodin present in the samples (Fig. 2). The quantity of aloin ranged from 0.15 to $0.45 \mathrm{mg} / \mathrm{g}$ and aloe-emodin from 0.09 to $0.29 \mathrm{mg} / \mathrm{g}$. Percent yield of aloin and aloeemodin has been calculated from the quantity of crude extract.

The linear regression of standard curve of aloin was determined with $\mathrm{R}^{2} \pm \mathrm{SD}=0.994 \pm 0.70 \%$. The linear regression line is $\mathrm{y}=445.152 \times+18,597.338$ (Fig. 2.a). The linear regression of standard curve of aloin-emodin was determined with $\mathrm{R}^{2} \pm \mathrm{SD}=0.982 \pm 0.2 .90 \%$. The linear regression line is $y=371.539 x+9935.154$ (Fig. 2.b).

\section{Antiplasmodial activity}

Crude aqueous extracts from different Indian Aloe vera samples were evaluated for antiplasmodial activity in terms of $\mathrm{EC}_{50}$ values. $\mathrm{EC}_{50}$ values for different crude extracts ranged from 0.289 to $1056 \mu \mathrm{g} / \mathrm{ml}$ (Table 1). Himachal Pradesh $(0.289 \mu \mathrm{g} / \mathrm{ml})$ sample showed the lowest $\mathrm{EC}_{50}$ value, which was followed by Uttar Pradesh $(0.299 \mu \mathrm{g} / \mathrm{ml})$ sample. Samples from West Bengal $(0.417 \mu \mathrm{g} / \mathrm{ml})$, Punjab $(0.407 \mu \mathrm{g} / \mathrm{ml})$ and Haryana $(0.472 \mu \mathrm{g} / \mathrm{ml})$ also showed good 

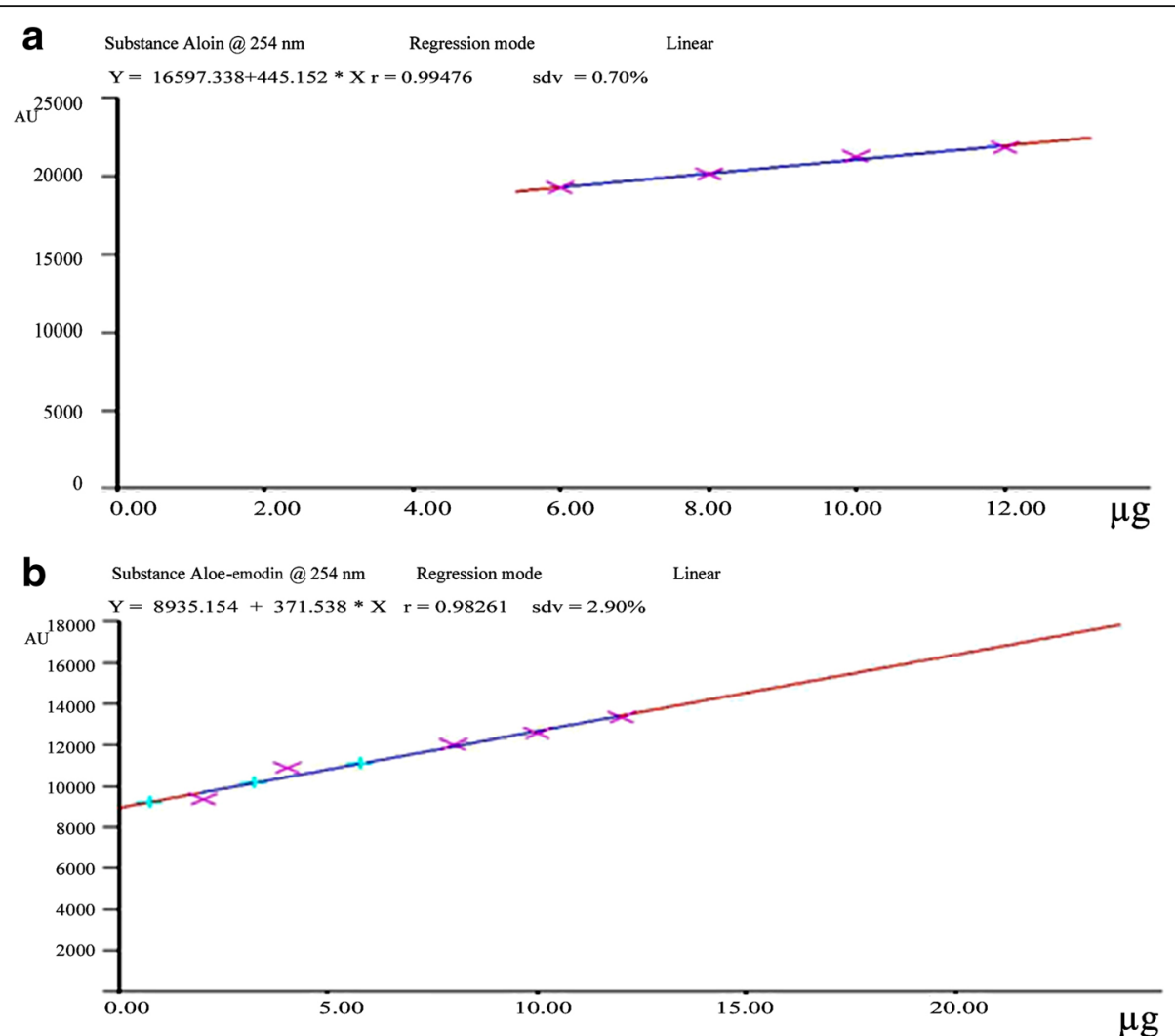

Fig. 2 Calibration curve showing linear regression of standard curve of aloin (a) and aloe-emodin (b)

antiplasmodial activity in comparison to other Aloe vera samples. Extracts from Telangana $(1.056 \mu \mathrm{g} / \mathrm{ml})$ and Rajasthan $(0.980 \mu \mathrm{g} / \mathrm{ml})$ samples showed comparatively least antiplasmodial potential. The reported $\mathrm{EC}_{50}$ values of aloin and aloe-emodin were $67 \mu \mathrm{g} / \mathrm{ml}$ and $22 \mu \mathrm{g} / \mathrm{ml}$ respectively for antiplasmodial activity (Table 1 ). The value of positive control Chloroquine was $0.034 \mu \mathrm{g} / \mathrm{ml}$. Antiplasmodial EC $\mathrm{E}_{50}$ values and quantity of aloin and aloe-emodin in different samples has been shown in Fig. 3. Correlation between different parameters has been shown in Fig. 4. Both the tested phytochemicals i.e. aloin and aloe-emodin showed negative correlation with temperature and rainfall. But the effect was more pronounced on aloin concentration.

\section{Discussion}

According to the WHO report (2016), there were an estimated 429,000 malaria deaths and 212 million new cases of malaria reported worldwide. This report

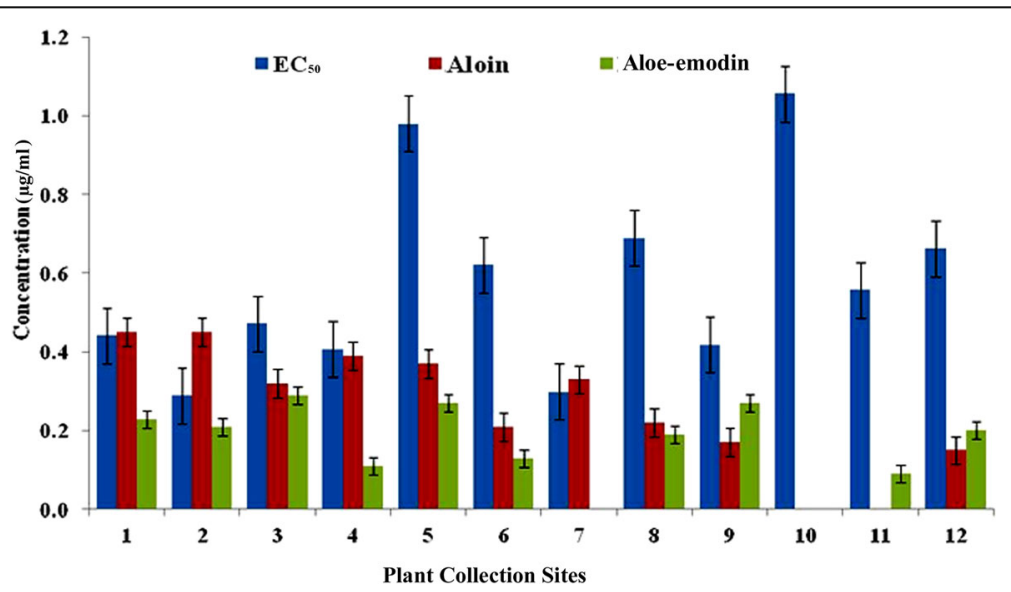

Fig. 3 Antiplasmodial EC $_{50}$ values, quantity of aloin and aloe-emodin from crude aqueous extracts of different Aloe vera samples 


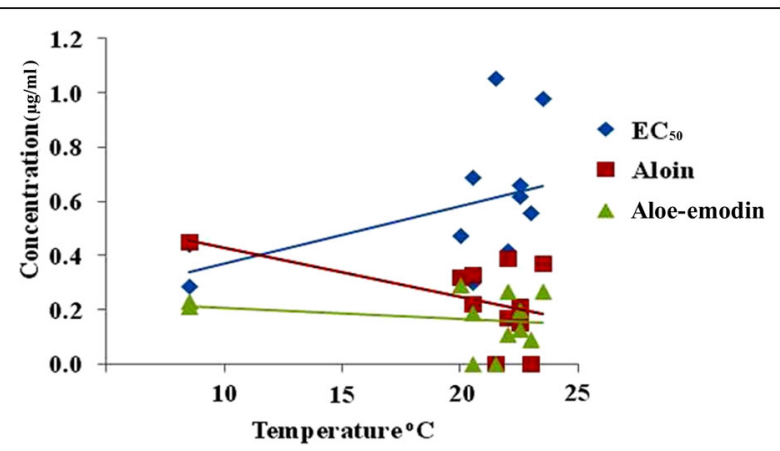

Fig. 4 Correlation analysis of temperature with aloin and aloe-emodin quantities and antiplasmodial $\mathrm{EC}_{50}$ values of different Aloe vera samples

revealed that 778,821 cases have been recorded with $P$. falciparum and 390,440 cases with $P$. vivax causing malarial infections in India. The WHO malaria report stated that African Region accounted for most global cases of malaria (90\%), followed by the South-East Asia Region (7\%) and the Eastern Mediterranean Region (2\%) [5]. The $22 \%$ of India's population live in high transmission, $67 \%$ live in low transmission areas and $11 \%$ live in malaria-free areas. The incidence of malaria in India accounted for $58 \%$ of cases in the South East Asia Region [33]. The central and eastern regions of India were reported for the most malaria cases particularly the eastern states of Odisha, West Bengal, and Jharkhand, the central states of Chhattisgarh and Madhya Pradesh, and the western states of Gujarat, Karnataka and Rajasthan, with the largest number of deaths reported in Odisha [34]. The diverse malaria epidemiology in India is mirrored by high diversity of malaria vector species, most of which exist as complexes comprising several cryptic species that vary in vectorial capacity $[35,36]$.

The climate varies from tropical monsoon in the south of the country to temperate in the north. Such climatic variation is due to a sharp temperature gradient caused by atmospheric changes in wind circulation and precipitation, lending to seasonally dependent asymmetric heating patterns of India's peripheral bodies of water and land [3]. The new medicines are needed both to meet the challenge of malaria eradication and to circumvent resistance. The regions and periods of the year of plant collection are known to play an important role in the variation of the type of compounds found in plants as well as their concentration. Geographical conditions are the main factors for genetic diversity that ultimately affect the phytoconstituents and medicinal properties of a plant [37]. Diversity among organisms is a result of variations in DNA sequences and environmental effects. Species with a wide geographic area generally have more genetic diversity [38]. According to previous findings it is suggested that environmental temperature has a significant effect on antioxidant activity evaluation and it is more pronounced in cold weather [39]. This promoted us to collect samples in the winter season (Jan- Feb 2013).

Aloe vera grows all over the India and has a wide range of bio- active constituents found in leaves [40]. Nine categories of phytochemical constituents of Aloe vera can be classified as, anthraquinones, inorganic compounds, amino acids, fatty acids, alkaloids, carbohydrates, enzymes, and vitamins along with other miscellaneous compounds [41]. Anthraquinones are the most important active ingredients of Aloe vera [42]. The antiplasmodial activity of $A$. vera may be explained in the light of the presence of anthraquinones and other quinoid compounds which exert good activity against $P$. falciparum [43]. The four main anthraquinones showing quite high medical values are aloin, aloe-emodin, aloe bitter and aloe lectin [44].

Phytochemical extraction from plant samples greatly relies upon solvent and extract preparation methods $[45,46]$. Water is the most polar of the solvents and confers negligible toxicity as such was used in this study $[47,48]$. Standardization of natural products is a complex task due to their heterogeneous composition, which is in the form of whole plant, plant parts, or extracts obtained thereof. To ensure reproducible quality of herbal products, proper control of starting material is of utmost importance. For identification of the crude drug it is best to possess the authentic reference standard of that particular crude drug and HPTLC is a valuable tool for the investigation of herbal products with respect to different aspects of their quality and quantity $[49,50]$.

In present study, HPTLC analysis showed the variability in the amount of aloin and aloe-emodin anthraquinones contents with respect to diverse climatic conditions of Indian agro- climatic zones. The quantity of aloin is found higher in comparison to aloe-emodin. The previous studies also revealed the higher amount of aloin compare to aloe-emodin [51-53]. Maximum amount of aloin was detected in Jammu and Kashmir and Himachal Pradesh (Highland zone, with average temperature $13.5{ }^{\circ} \mathrm{C}$ and average rainfall $1011 \mathrm{~mm}$ and $1251 \mathrm{~mm}$ respectively) samples where as that of aloe-emodin in Punjab (Semi-arid zone, with average temperature of $25^{\circ} \mathrm{C}$ and average rainfall $649 \mathrm{~mm}$ ) sample.

There is not too much literature available on evaluation of antiplasmodial potential of Aloe vera but the plant has been reported several times as a antimalarial remedy in folk medicine system [25, 26]. Efforts are now being directed towards the discovery and development of new chemically diverse antimalarial agents. The South African Vitex spp. showed significant activity against $P$. falciparum chloroquine- 
resistant FCR-3, with $\mathrm{IC}_{50}$ values ranging from $9.16 \pm 1.37 \mu \mathrm{g} / \mathrm{ml}$ to $16.02 \pm 3.07 \mu \mathrm{g} / \mathrm{ml}$. [54]. The plant extracts of 134 species tested for in vitro activity against a Plasmodium falciparum strain D10 using the parasite lactate dehydrogenase (pLDH) assay showed the $49 \%$ promising antiplasmodial activity $\left(\mathrm{IC}_{50} \leq 10 \mathrm{~g} / \mathrm{ml}\right)$, while $17 \%$ were found to be highly active $\left(\mathrm{IC}_{50} \leq 5 \mathrm{~g} / \mathrm{ml}\right)$ [55].

Larvicidal activity of Aloe species growing in Kenya, namely Aloe turkanensis, Aloe ngongensis and Aloe fibrosa tested against A. gambie third instar larvae showed $60 \%$ mortality at concentration of $2 \mathrm{mg} / \mathrm{ml}$ or $0.2 \% w / v$ [56]. Several anthraquinones extracted from different plant parts strongly inhibited in vitro growth of a chloroquine sensitive strain of Plasmodium falciparum (3D7) [57]. Anthraquinones may generate reactive oxygen and thus inactivate malaria parasites (Plasmodium falciparum, $P$. vinckei and $P$. berghei) $[58,59]$. Latex leaf extract of Aloe citrine showed antiplasmodial activity due to presence of anthrone, homonataloin $\mathrm{A} / \mathrm{B}$ as a major constituent [60]. On the basis of our present findings, Himachal Pradesh sample showed the lowest $\mathrm{EC}_{50}$ value (0.289) which means highest antiplasmodial activity in comparison to other Aloe vera samples. Aloe vera is a cold sensitive plant. During stress more phytochemicals are produced in plants to withstand the adverse conditions. Studies conducted on plants in stress conditions showed higher production of flavonoids, anthocyanins and mucilaginous substances [53].

In the present study $\mathrm{EC}_{50}$ values of aloin and aloeemodin were $67 \mu \mathrm{g} / \mathrm{ml}$ and $22 \mu \mathrm{g} / \mathrm{ml}$ respectively for antiplasmodial activity against a chloroquine (CQ)sensitive strain of $P$. falciparum (MRC-2). As both the anthraquinones tested in the study showed less antiplasmodial potential in comparison to crude extracts of different Aloe vera samples, these data suggest that the activity observed may be due to the synergistic effect of aloin, aloe-emodin and presence of other more active compounds in the extracts of Aloe vera plant. In contrast the previous study on Aloe extracts revealed that $\mathrm{IC}_{50}$ value for aloin was $169.76 \pm 11.5 \mu \mathrm{g} / \mathrm{ml}$ against the chloroquine-sensitive 3D7 strain [27]. Dai et al. [61] reported the $\mathrm{IC}_{50}$ value for antiplasmodial activity of aloe-emodin was $50 \mu \mathrm{g} /$ $\mathrm{ml}$ isolated from ethanol extract of South African plant Kniphofia ensifolia against $P$. falciparum Dd2 strain. They also showed that esterification of the primary hydroxyl group of aloe-emodin with various carboxylic acids increased its antiplasmodial activity, with the most potent analogue being the 3,4dimethylcaffeic acid derivative with an $\mathrm{IC}_{50}$ value of $1.3 \pm 0.2 \mu \mathrm{M})$ over 40 times than that of aloeemodin. The biological activities of Aloe vera are due to the synergistic action of a variety of compounds, rather than from a single defined component [62, 63]. Significant correlation between quantities of both the anthraquinones used as marker compounds and $\mathrm{EC}_{50}$ values of the different Aloe vera extracts proves the plant as a prospective antimalarial remedy.

Traditional medicine and ethnobotanical information play an important role today as subject for scientific research, particularly when the literature and field work data have been properly evaluated. From the present work, it may be concluded that agro-climatic locations along with temperature and rainfall have significant effects on the Aloe vera plant phytoconstituents and its antimalarial potential. However, there is still a need to investigate the effects of different biotic and abiotic factors on Aloe vera. In future, it is also required to isolate antiplasmodial molecules from crude extracts of Aloe vera to enhance the antimalarial potential of the plant under cold stress. Plant growth and productivity are greatly affected by environmental stresses such as dehydration, high salinity, low temperature and biotic pathogen infection. Many plant genes are regulated in response to biotic and abiotic stresses and their gene products function in stress response. Such genetic systems are thought to be very important in increasing tolerance of plants to these stresses as well as in management for successful crop cultivation [64].

\section{Conclusion}

Present work indicates that diverse climatic factors affect the quantity of aloin and aloe-emodin in different Aloe vera extracts, which plays a significant role in antiplasmodial potential of the plant. HPTLC analysis showed the variability in the amount of both the tested anthraquinone contents with respect to diverse climatic conditions of Indian agro-climatic zones. Significant correlation has been found between quantities of used marker compounds and $\mathrm{EC}_{50}$ values of the different Aloe vera plant samples. Study also concludes that north Indian Aloe vera samples are more potent against malaria parasite as compared to south Indian samples. These data lend support to the traditional use of Aloe vera in the treatment of malaria and further investigation would be worthwhile. Further studies to determine whether aloin and aloin-emodin do in fact act as synergistically and whether there are other antiplasmodial compounds present in the extract would also be valuable. Study also concludes that north Indian Aloe vera samples are more potent against malaria parasite as compared to south Indian samples. This study may help in selection, standardization and to formulate new and more potent antimalarial drugs of natural origin. 


\section{Abbreviations}

${ }^{\circ} \mathrm{C}$ : Degree celcius; ACT: Artemisinin-based combination therapy; $\mathrm{cm}$ : Centi meter; CQ: Chloroquine; EC 50 : Effective concentration at 50\%; GC: Gas Chromatography; HEPES: 2-[4-(2-hydroxyethyl) piperazin-1-yl] ethanesulfonic acid; HPLC: High Performance Liquid Chromatography; HPTLC: High Performance Thin Layer Chromatography; MIC: Minimum Inhibitory Concentration; mm: Milli meter; $\mathrm{nLs}^{-1}$ : Nano liter per second; $\mathrm{nm}$ : Nano meter; $\mathrm{pH}$ : Hydrogen potential; $\mathrm{R}^{2}$ : Regression Cofficient; RBC: Red blood corpuscles; Rf: Retardation factor $\mu \mathrm{g} / \mathrm{ml}$; RPMI-1640 medium: Roswell Park Memorial Institute Medium; SPSS: Statistical Package for the Social Sciences TLC: Thin layer chromatography; v/v/v: Volume by volume by volume; WHO: World Health Organization

\section{Acknowledgments}

SK, MY, AY and PR acknowledge the award of UGC- BSR fellowship.

\section{Funding}

The research was financially supported by UGC, New Delhi under UGC-SAP (No. F.3 20/2012, SAP II) and DST, New Delhi for providing infrastructure grant under DST FIST programme.

\section{Availability of data and materials}

Data and material is available in the research paper itself

\section{Authors' contributions}

Collection, acquisition of data and analysis: SK. Design and interpretation of data: MY, AY. Statistical analysis: PR. Supervision of the study and drafting of the manuscript: JPY. All authors read and approved the final manuscript.

\section{Ethics approval and consent to participate}

The study did not need ethical approval and participate consent.

\section{Consent for publication}

All the authors have approved the manuscript for submission.

\section{Competing interests}

The authors declare no conflicting of interest.

\section{Publisher's Note}

Springer Nature remains neutral with regard to jurisdictional claims in published maps and institutional affiliations.

\section{Received: 8 June 2017 Accepted: 13 July 2017}

\section{Published online: 17 July 2017}

\section{References}

1. Sumsakul W, Plengsuriyakarn T, Chaijaroenkul W, Viyanant V, Karbwang J, $\mathrm{Na}$-Bangchang K. Antimalarial activity of plumbagin in vitro and in animal models. BMC Complement Altern Med. 2014;14(15):1-6.

2. World Health Organization. World Malaria Report Available: http://www who.int/malaria/world_malaria_report_2010/worldmalariareport2010.pdf. 2010; Accessed 6 Dec 2011.

3. Das A, Anvikar AR, Cator LJ, Dhiman RC, Eapen A, Mishra N, Nagpal BN, Nanda N, Raghavendra K, Read AF, Sharma SK. Malaria in India: the center for the study of complex malaria in India. Acta Trop. 2012;121(3):267-73.

4. Jensen M, Mehlhorn H. Seventy-five years of Resochin ${ }^{\circledast}$ in the fight against malaria. Parasitol Res. 2009;105(3):609-27.

5. World Malaria Report, World Health Organization, Geneva, Switzerland; 2016 p. 57.

6. Kone AK, Sagara I, Thera MA, Dicko A, Guindo A, Diakite S, Kurantsin-Mills J, Djimde A, Walcourt A, Doumbo O. Plasmodium falciparum clearance with artemisinin-based combination therapy (ACT) in patients with glucose-6phosphate dehydrogenase deficiency in Mali. Malar J. 2010;9(1):332.

7. Modrzynska KK, Creasey A, Loewe L, Cezard T, Borges ST, Martinelli A, Rodrigues L, Cravo P, Blaxter M, Carter R, Hunt P. Quantitative genome re-sequencing defines multiple mutations conferring chloroquine resistance in rodent malaria. BMC Genomics. 2012;13(1):106

8. World Malaria Report. World health organization. Geneva: Switzerland; 2010

9. Maguire JD, Sumawinata IW, Masbar S, Laksana B, Prodjodipuro P, Sismadi P, Mahmud N, Bangs MJ, Baird JK, Susanti I. Chloroquine-resistant Plasmodium malariae in south Sumatra. Indonesia The Lancet. 2002;360(9326):58-60.
10. Nwaka S. Drug discovery and beyond: the role of public-private partnerships in improving access to new malaria medicines. Trans R Soc Trop Med and Hyg. 2005;99(Suppl 1):20-9.

11. Jacob EJ. Natural products-based drug discovery: some bottlenecks and considerations. Curr Sci. 2009;96(6):753-4.

12. Robert A, Benoit-Vical F, Dechy-Cabaret O, Meunier B. From classical antimalarial drugs to new compounds based on the mechanism of action of artemisinin. Pure Appl Chem. 2001;73(7):1173-88.

13. Muthaura CN, Keriko JM, Derese S, Yenesew A, Rukunga GM. Investigation of some medicinal plants traditionally used for treatment of malaria in Kenya as potential sources of antimalarial drugs. Exp Parasitol. 2011;127(3):609-26.

14. Pillay P, Maharaj VJ, Smith PJ. Investigating south African plants as a source of new antimalarial drugs. J Ethnopharmacol. 2008;119(3):438-54.

15. Krishnarajua AV, Rao TVN, Sundararajua D, Vanisreeb M, Tsayb H, Subbaraju GV. Assessment of bioactivity of India medicinal plants using brine shrimp (Artemia salina) lethality assay. Int J Appl Sci Eng. 2005;3(2):125-34.

16. Choudhary N, Sekhon BS. An overview of advances in the standardization of herbal drugs. J Pharm Educ Res. 2011;2(2):55

17. Jain A, Lodhi S, Singhai AK. Simultaneous estimation of quercetin and rutin in Tephrosia purpurea Pers by high performance thin layer chromatography. Asian J Tradit Med. 2009;4(3):104-9.

18. Eggli U. Illustrated handbook of succulent plants. Monocotyledons: Springer; 2001.

19. Eshun K, Qian H. Aloe vera: a valuable ingredient for the food, pharmaceutical and cosmetic industries-a review. Crit Rev Food Sci Nutr. 2004:44:91-6.

20. Boudreau MD, Beland FA. An evaluation of the biological and toxicological properties of Aloe barba- densis (miller), Aloe vera. J Environ Sci Health part C. 2006:24(1):103-54.

21. Rishi P, Rampuria A, Tewari R, Koul A. Phyto- modulatory potentials of Aloe vera against Salmonella OmpR-mediated inflammation. Phytother Res. 2008;22(8):1075-82

22. Wintola OA, Afolayan AJ. Phytochemical constituents and antioxidant activities of the whole leaf extract of Aloe ferox mill. Pharmaco Mag. 2011:7(28):325-33.

23. Langmead L, Makins RJ, Rampton DS. Anti-inflammatory effects of Aloe vera gel in human colorectal mucosa in vitro. Aliment Pharmacol Therap. 2004;19:521-7.

24. Jayaprakasha GK, Singh RP, Sakariah KK. Antioxidant activity of grape seed (Vitis vinifera) extracts on peroxidation models in vitro. Food Chem. 2001;73:285-90.

25. Ali AA, Al-Rahwi K, Lindequist U. Some medicinal plants used in Yemen herbal medicine to treat malaria. Afr J Trad CAM. 2004;1:72-6.

26. Asiimwe S, Namutebi A, Borg-Karlson AK, Mugisha MK, Kakudidi EK, Hannington OO. Documentation and consensus of indigenous knowledge on medicinal plants used by the local communities of western Uganda. J Nat Prod Plant Resour. 2014;4(1):34-42.

27. Van Zyl RL, Viljoen AM. In vitro activity of aloe extracts against Plasmodium falciparum. S Afr J Bot. 2002;68:106-10.

28. Neuwinger HD. African Ethnobotany. Poisons and Drugs; London: Chapman \& Hall; 1996. p. 3-9.

29. Surjushe A, Vasani R, Saple DG. Aloe Vera: a short review. Indian J Dermatol. 2008;53(4):163-6.

30. Venkatesalu V, Gopalan N, Pillai CR, Singh V, Chandrasekaran M, Senthilkumar A, Chandramouli N. In vitro antiplasmodial activity of some traditionally used medicinal plants against Plasmodium falciparum. Parasitol Res 2012;111(1):497-501.

31. Trager W, Jensen JB. Human malaria parasites in continuous culture. Science. 1976;193(4254):673-5.

32. World Health Organization. In vitro micro test (Mark III) for the assessment of the response of Plasmodium falciparum to chloroquine, mefloquine, quinine, amodiaquine, sulfadoxine/pyrimethamine and artemisinin. WHO, Geneva. 2001.

33. World Malaria Report, World Health Organization, Geneva, Switzerland, 2014

34. Joshi H, Prajapati SK, Verma A, Kang'a S, Carlton JM. Plasmodium vivax in India. Trends Parasitol. 2008:24(5):228-35.

35. Dash AP, Adak T, Raghavendra K, Singh OP. The biology and control of malaria vectors in India. Currnt Sci. 2007:92:1571-8.

36. Singh V, Mishra N, Awasthi G, Dash AP, Das A. Why is it important to study malaria epidemiology in India? Trends Parasitol. 2009;25(10):452-7.

37. Kumar S, Yadav M, Yadav A, Yadav JP. Comparative analysis of antimicrobial activity of methanolic extracts of Aloe vera and quantification of aloe- emodin collected from different climatic zones of India. Arch Clin Microb. 2015;6(2):1-10. 
38. Wilikie SE, Issac PG, Slater RJ. Random amplified polymorphic DNA (RAPD) markers for genetic analysis in Allium. Theor Appl Genet. 1993;87:668-72.

39. Iqbal S, Bhanger MI. Effect of season and production location on antioxidant activity of Moringa oleifera leaves grown in Pakistan. J Food Comp Anal. 2006;19:544-51.

40. Thu K, Mon YY, Khaing TA, Tun OM. Study on phytochemical properties, antibacterial activity and cytotoxicity of Aloe vera L. World Acad Sci Eng Technol. 2013;77:102-6.

41. Kumar S, Yadav JP. Ethnobotanical and pharmacological properties of Aloe vera: a review. J Med Plants Res. 2014;48(8):1387-98.

42. Yan L. The health efficacy of aloe and its development and utilization. Asian Soc Sci. 2009;5(9):151-4.

43. Sittie AA, Lemmich E, Olsen CE, Hviid L, Kharazmi A, Nkrumah FK, Christensen SB. Structure-activity studies: in vitro antileishmanial and antimalarial activities of anthraquinones from Morinda lucida. Planta Med. 1999;65(3):259-61.

44. Li-chuan WA. Research advance on the main chemical components of aloes leaf and their efficacies. Anim Husbandry Feed Sci. 2009;30(1):25-6.

45. Ellof JN. Which extractant should be used for the screening and isolation of antimicrobial components from plants? J Ethnopharmacol. 1998;60:1-8.

46. Adesanya SA. From nature to drugs. Theories and realities. Inaugural lecture series. lle-lfe, Osun State Nigeria: Obafemi Awolowo University Press Ltd. 2005:181.

47. Parekh J, Jadeja D, Chanda S. Efficacy of aqueous and methanol extracts of some medicinal plants for potential antibacterial activity. Turk J Biol. 2005; 29:203-21.

48. Leira HL, Fonnum F, Syversen T. Organic solvents. In: Ballatyne, Marrs, Syversen. editors. General and Applied Toxicology, 3rd edition. London: Wiley. 2009:3285-308.

49. Sonawane SD, Nirmal SA, Patil AN, Pattan SR. Development and validation of HPTLC method to detect curcumin and gallic acid in polyherbal formulation. J Liq Chrom Relat Tech. 2011;34(20):2664-73.

50. Reich E, Schibli A. High performance thin layer chromatography for the analysis of medicinal plants. New York: Thieme; 2007. p. 130-62.

51. Suga T, Hirata T. The efficacy of the aloe plants chemical-constituents and biological-activities. Cosmet Toiletries. 1983;98(6):105-8.

52. Van Wyk BE, Yenesew A, Dagne E. Chemotaxonomic significance of anthraquinones in the roots of Asphodeloideae (Asphodelaceae). Biochem Syst Ecol. 1995;23(3):277-81.

53. Dagne E, Bisrat D, Viljoen A, Van Wyk BE. Chemistry of Aloe species. Curr Org Chem. 2000:4:1055-78.

54. Nyiligira E, Viljoen AM, Van Heerden FR, Van Zyl RL, Van Vuuren SF, Steenkamp PA. Phytochemistry and in vitro pharmacological activities of south African Vitex (Verbenaceae) species. J Ethnopharmacol. 2008;119(3):680-5.

55. Clarkson C, Maharaj VJ, Crouch NR, Grace OM, Pillay P, Matsabisa MG, et al. In vitro antiplasmodial activity of medicinal plants native to or naturalised in South Africa. J Ethnopharmacol. 2004;92(2):177-91.

56. Matasyoh JC, Wathuta EM, Kariuki ST, Chepkorir R, Kavulani J. Aloe plant extracts as alternative larvicides for mosquito control. Afr J Biotechnol. 2008;7(7):912-5.

57. Osman CP, Ismail NH, Ahmad R, Ahmat N, Awang K, Jaafar FM. Anthraquinones with antiplasmodial activity from the roots of Rennellia elliptica Korth.(Rubiaceae). Molecules. 2010;15(10):7218-26.

58. El Heiga LA, Katzhendler J, Gean KF, Bachrach U. Antimalarial activity of substituted anthraquinones. Biochem Pharmacol. 1990;39(10):1620-3.

59. Kanokmedhakul K, Kanokmedhakul S, Phatchana R. Biological activity of anthraquinones and triterpenoids from prismatomeris fragrans. J Ethnopharmacol. 2005;100(3):284-8.

60. Girma B, Bisrat D, Asres K. Antimalarial evaluation of the leaf latex of Aloe citrina and its major constituent. Ancient Sci Life. 2015;34:142-6.

61. Dai Y, Harinantenaina L, Bowman JD, Da Fonseca IO, Brodie PJ, Goetz M, Cassera MB, Kingston DGI. Isolation of antiplasmodial anthraquinones from Kniphofia ensifolia, and synthesis and structure-activity relationships of related compounds. Bioorganic \& Med Chem. 2014;22(1):269-76.

62. Hamman JH. Composition and applications of Aloe vera leaf gel. Molecules. 2008;13(8):1599-616

63. Kaplan F, Kopka J, Sung DY, Zhao W, Popp M, Porat R, Guy CL. Transcript and metabolite profiling during cold acclimation of Arabidopsis reveals an intricate relationship of cold-regulated gene expression with modifications in metabolite content. Plant J. 2007;50(6):967-81.

64. Singh A, Sengar K, Sengar RS. Gene regulation and biotechnology of drought tolerance in rice. Int J Biotechnol Bioeng Res. 2013;4(6):547-52. 